\title{
Better Wavelength for Cadmium Analysis between 228.8 Nanometer and 228.9 Nanometer in Atomic Absorption Spectrophotometry
}

Yong Kook Kim ${ }^{1}$, Byung Hoon Park ${ }^{2}$, Hyeonhi R. Park ${ }^{3}$, Jiah A. Kim ${ }^{4}$, Rosa Kim ${ }^{5}$, Alain Hamon ${ }^{6}$, Sohwa T. Kim ${ }^{7}$, Ye Ram Jeong ${ }^{8}$, Chan Hee Cho ${ }^{9}$, Jun Su Park ${ }^{10}$, Yubin Kim ${ }^{11}$, Chae Bin Gwak ${ }^{12}$, Jiho Lee ${ }^{13}$, Seung Hwan $\mathrm{Han}^{14}$, Jeong Seok $\mathrm{Oh}^{15}$, Sunho Kim ${ }^{16}$, Jun Young Lee ${ }^{17}$, Sangdeog A. $\operatorname{Kim}^{18^{*}}$

${ }^{\mathrm{T}}$ Department of Dairy Science, Chungnam National University, Daejeon, Republic of Korea (ROK)

${ }^{2}$ Department of Companion Animal and Animal Resources Science, Joongbu University, Kumsan, ROK

${ }^{3}$ Department of Elderly care and welfare, Joongbu University, Kumsan, ROK

${ }^{4}$ Départment d'Expertise economique, Université de Paris-Est Creteil, Paris, France

${ }^{5}$ Spécialité d'Economie politique, Ecole des Hautes Etudes en Sciences Sociales, Paris, France

${ }^{6}$ Groupe scolaire iféa - Émilie du Châtelet, 92110 Clichy, France

${ }^{7}$ Department of French language and literature, Seoul Women's University, Seoul, ROK

${ }^{8,9}$ Department of Companion animal and animal resources science, Joongbu University, Kumsan, ROK

${ }^{10-16}$ Department of Companion animal and animal resources science, Joongbu University, Kumsan, ROK

${ }^{17}$ Department of Companion animal and animal resources science, Joongbu University, Kumsan, ROK

${ }^{18}$ Department of Companion animal and animal resources science, Joongbu University, Kumsan, ROK

\section{*Corresponding Author}

Sangdeog A. Kim

\section{Article History}

Received: 16.09.2020

Accepted: 23.09 .2020

Published: 27.09.2020

Abstract: Several wave-lengths can be used for an element analysis on atomic absorption spectrophotometry [1]. Et Park et al. [2] wrote that the wave-length of cobalt determination can be changed. So this time the researchers tried to find out the better wave length for cadmium $(\mathrm{Cd})$ analysis. The researchers found that the flat state from the minus to the plus seems to be good for the appropriate $\mathrm{Cd}$ analysis (Figure 1). There is another thing for the appropriate wave length; the thing is the pillar near the 228.9 nanometer.

Keywords: 228.9 nanometer, atomic absorption spectrophotometry, cadmium, flat state, pillar, wave-length.

\section{INTRODUCTION}

Several wavelengths can be used for an element analysis on atomic absorption spectrophotometry [1]. Et Park et al. [2] wrote that the wave length of cobalt determination can be changed. So this time the researchers tried to find out the better wave length for cadmium (Cd) analysis.

\section{Materials and Methods}

The used atomic absorption spectrophotometer was Varian product. And it is well known that $228.8 \mathrm{~nm}$ is advised for Cd analysis [1], but the researchers tried to treat the condition of $228.9 \mathrm{~nm}$.

\section{Results AND Discussion}

Figure 1 (the figure number 24) shows the change of absorption for cadmium (Cd) analysis from the right part to the left part, and the position of 228.8 nanometer $(\mathrm{nm})$ was indicated good for the Cd analysis. It is because the direction of absorption was changed from the minus to plus. But it is shown that the better position seems to be $228.9 \mathrm{~nm}$, it is because this spot seems to the just point of turning point from minus to plus.

Copyright @ 2020: This is an open-access article distributed under the terms of the Creative Commons Attribution license which permits unrestricted use, distribution, and reproduction in any medium for non commercial use (NonCommercial, or CC-BY-NC) provided the original author and source are credited. 
Figure 2 (the figure number 23) also shows the similar change of value from the minus on the right side to the plus on the left side. And there is a specific sign of large pillar.

The researchers found that the flat condition from the minus to the plus seems to be good for the appropriate Cd analysis (Figure 1). There is ananother thing for the appropriate wave length; the thing is the pillar near the 228.9 nanometer.

(Figure1. The change of absorption for cadmium (Cd) analysis from the right part to the left part, and the position of 228.8 nanometer $(\mathrm{nm})$.

(Figure 2. The change of value from the minus side on the right side to the plusone on the left side.)

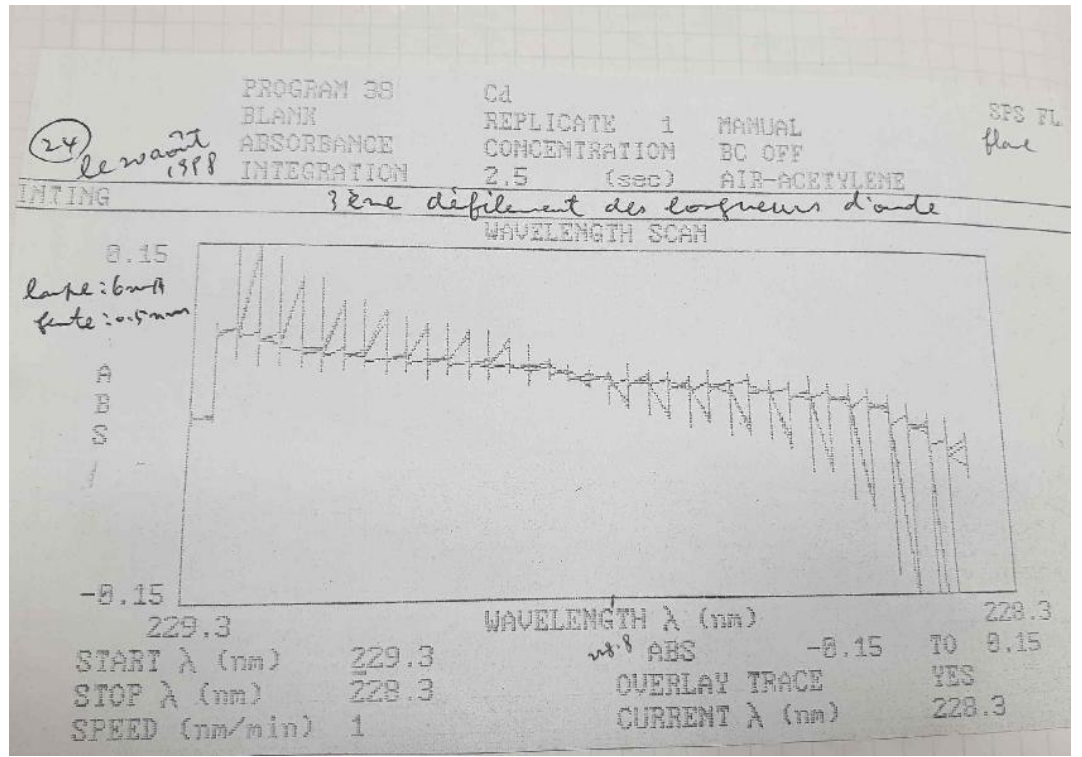

Fig-1: The change of absorption for cadmium (Cd) analysis from the right part to the left part, and the position of 228.8 nanometer (nm)

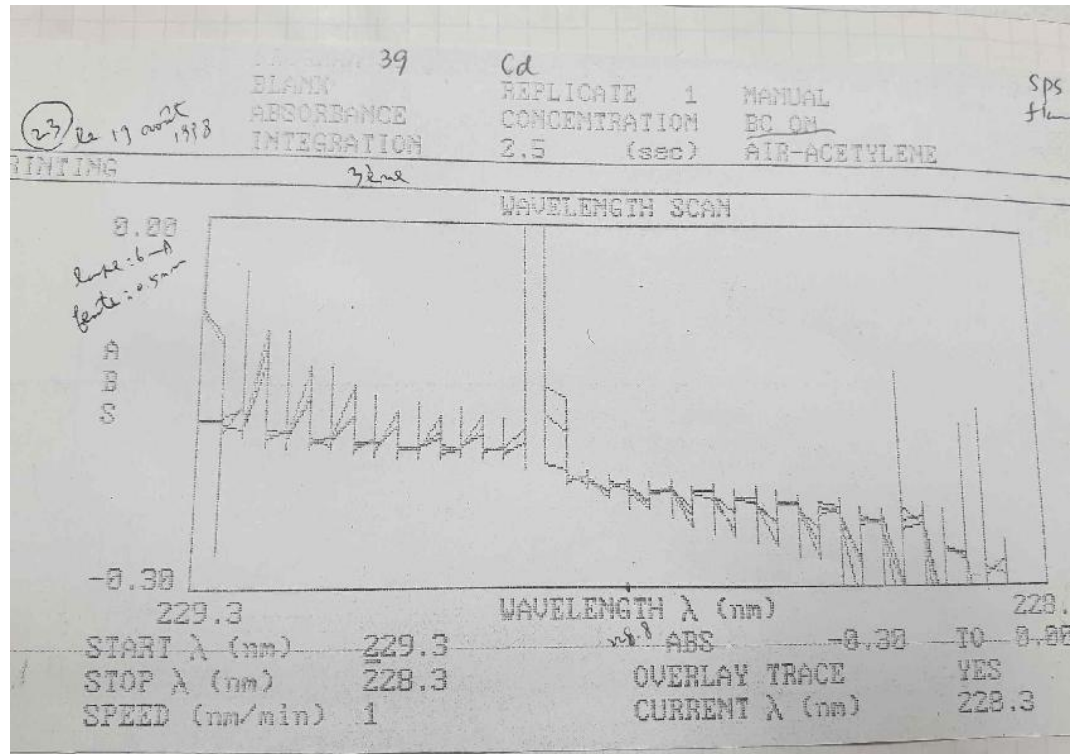

Fig-2: The change of value from the minus side on the right side to the plus one on the left side

\section{Further suggestions}

The practical analysis is necessary for the certification of this theorethical work.

\section{Conflicts of interests}

There are no conflicts of interests to declare. 


\section{ACKNOWLEDGEMENTS}

We thank Mr Yeonghag Park and Mrs Hilye Sarah Kim, Mr Ilsoo Joseph Kim and Mrs Bohwa Kim and Ms Jieun Agatha Kim and Mr Kunjoo Daegon-Andrea Kim, Father Jean Blanc and Father Hifumi Iwazaki, Professor Tae Song Koh and Professor Shigekata Yoshida, Mrs Tamako Hayashi and Mr Yoshihiro Hayashi, Mrs Francine Tenaillon and Professor Nicolas Tenaillon, Mrs SookJa Nam and Mrs Sookja Martha Min and Mrs Kisoon Cecile Song, Professor Alain Bermond and Mr Stéphanie Debrie, the members of Daejeon Ludovich of Ordo Franciscanus Saecularis(OFS) and the members of Daejeon Nae-dong Catholic Church.

\section{REFERENCES}

1. Pinta, M., Baudin, G., Bourdon, R., Burelli, F., Condylis, A., Ecrement, F., Hocquaux, H., Kovacsik, G., Kuhn, V., Laporte, J., Normand, J., Riandey, C., Ropert, M.E., Rousselet, F., Ryser, S., Thuillier, F., Voinovitch, I. (1979). Spectrometrie d'absorption atomique. Application a l'analyse chimique (2e edition). Tome I. Masson. O.R.S.T.O.M. Paris, 40-219.

2. Park, B.H., Kim, Y.H., Lee, J.D., Park, J.W., Lee, H.J., Yoo, S.M., Cho, D.K., Park, B.K., Song, D.M., Kim, D.W., Kim, S.A. (2011). Sorghum cobalt analysis on not determined wave length with atomic absorption spectrophotometer on background correction mode. African Journal of Biotechnology, 10(47): 9677-9682. 